\title{
Idiopathic noncirrhotic portal hypertension: current perspectives
}

\author{
This article was published in the following Dove Press journal: \\ Hepatic Medicine: Evidence and Research \\ 27 July 2016 \\ Number of times this article has been viewed
}

\author{
Oliviero Riggio' \\ Stefania Gioia' \\ Ilaria Pentassuglio' \\ Valeria Nicoletti' \\ Michele Valente ${ }^{2}$ \\ Giulia d'Amati² \\ 'Department of Clinical Medicine, \\ Center for the Diagnosis and \\ Treatment of Portal Hypertension, \\ ${ }^{2}$ Department of Radiological, \\ Oncological, and Pathological \\ Sciences, Sapienza University of Rome, \\ Rome, Italy
}

\begin{abstract}
The term idiopathic noncirrhotic portal hypertension (INCPH) has been recently proposed to replace terms, such as hepatoportal sclerosis, idiopathic portal hypertension, incomplete septal cirrhosis, and nodular regenerative hyperplasia, used to describe patients with a hepatic presinusoidal cause of portal hypertension of unknown etiology, characterized by features of portal hypertension (esophageal varices, nonmalignant ascites, porto-venous collaterals), splenomegaly, patent portal, and hepatic veins and no clinical and histological signs of cirrhosis. Physicians should learn to look for this condition in a number of clinical settings, including cryptogenic cirrhosis, a disease known to be associated with INCPH, drug administration, and even chronic alterations in liver function tests. Once INCPH is clinically suspected, liver histology becomes mandatory for the correct diagnosis. However, pathologists should be familiar with the histological features of INCPH, especially in cases in which histology is not only requested to exclude liver cirrhosis.
\end{abstract}

Keywords: idiopathic portal hypertension, obliterative portal venopathy, esophageal varices, splenomegaly

\section{Historical background}

In 1889, Guido Banti, an Italian pathologist, described a disease with splenomegaly and hypersplenism not associated with any known hematological disease. ${ }^{1}$ He considered the spleen as the primary site of the alterations leading to sclerosis of the splenic and portal veins. Over the years, it became clear that the patients described by Banti may have been affected by a variety of vascular and liver disorders, difficult to define, given the diagnostic facilities available at that time. In 1962, a syndrome distinct from both cirrhosis and extrahepatic obstruction of the portal vein was described in patients with portal hypertension from northern India. ${ }^{2}$ The disease was called noncirrhotic portal fibrosis. ${ }^{3}$ In 1965, Mikkelsen et $\mathrm{al}^{4}{ }^{4}$ identified a concentric thickening of the portal vein and its radicles and called this condition "hepatoportal sclerosis" while Boyer et $\mathrm{al}^{5}$ studying cases of noncirrhotic portal fibrosis in India adopted the term idiopathic portal hypertension. In the Western world, terms such as hepatoportal sclerosis, idiopathic portal hypertension, incomplete septal cirrhosis, and nodular regenerative hyperplasia (NRH) have been used over the years to describe the histological alterations observed in patients with portal hypertension in absence of cirrhosis, thus increasing the confusion about the syndrome. Finally, in 2011, a group of European experts in portal hypertension proposed the term idiopathic noncirrhotic portal hypertension (INCPH) to be used in future collaborative studies. ${ }^{6}$
Correspondence: Oliviero Riggio

Department of Gastroenterology, Centro di Riferimento per l'lpertensione Portale., II Gastroenterologia, Dipartimento di Medicina Clinica, "Sapienza"

Università di Roma, Viale dell'Università

37,00185 Rome, Italy

Tel +39649972001

Fax +3964453 319

Email oliviero.riggio@uniromal.it 
In Western countries, INCPH is considered a rare disease and few series of patients have been collected and described so far. ${ }^{7-10}$ However, in our opinion, due to low level of clinical suspicion, INCPH may be missed or confused with more frequent diseases. For example, it is possible that in a patient with esophageal varices, mild or no alterations in liver function tests, and no evidence of etiological factors, the diagnosis of "compensated cryptogenic cirrhosis" may be made without taking into consideration INCPH. Moreover, INCPH may be frequently associated with a number of diseases and drug treatment and should be actively searched in these instances. Finally, evidence is increasing that among patients with chronic alanine aminotransferase (ALT)/ aspartate aminotransferase (AST) elevation of unknown origin, histological sings of INCPH can be found at liver biopsy, suggesting the possibility of diagnosing INCPH at an early stage, even before the clinical evidence of portal hypertension. ${ }^{11,12}$

In this review, we will try to answer some clinical questions concerning the diagnosis of INCPH.

\section{What is the clinical manifestation of INCPH?}

The majority of patients with INCPH present in early adulthood with a complication of portal hypertension usually variceal bleeding. At the diagnosis, they present signs of portal hypertension (esophageal or gastric varices). Not infrequently, the patients have been referred to a hematologist because of thrombocytopenia and splenomegaly. ${ }^{13}$ Ascites may occur, more frequently as a transient phenomenon, consequent to other complications, such as gastrointestinal bleeding and infections..$^{7-9}$

Hepatic encephalopathy may also occur, more frequently as a subclinical cognitive impairment, but $\sim 7 \%-8 \%$ of the patients experiences at least one episode of overt hepatic encephalopathy. ${ }^{8}$ In INCPH, the cognitive impairment is mainly related to the presence of large portal-systemic shunts, either spontaneous or iatrogenic. ${ }^{14}$ Portal vein thrombosis is a common complication of INCPH..$^{915}$ HIV infection and variceal bleeding at diagnosis ${ }^{8}$ have been reported as risk factors for PVT.

\section{How can the diagnosis of INCPH be made?}

INCPH is a hepatic presinusoidal cause of portal hypertension of unknown etiology, characterized by features of portal hypertension (esophageal varices, nonmalignant ascites, porto-venous collaterals) and splenomegaly, with or without hypersplenism. Portal and hepatic veins should be patent. Usually, liver function is preserved and the hepatic venous pressure gradient (HVPG) is slightly elevated, according to the presinusoidal nature of portal hypertension.

No clinical or laboratory alterations are pathognomonic of INCPH. The diagnosis should be made at the end of a complete diagnostic workout, aimed at excluding other causes of portal hypertension. This should include a detailed medical history to investigate possible liver diseases; liver imaging to evaluate the patency of the splanchnic venous axis and rule out chronic portal vein thrombosis or obstruction of the hepatic veins; and appropriate laboratory tests to exclude chronic viral hepatitis B and/or C, nonalcoholic or alcoholic steatohepatitis, autoimmune hepatitis, hereditary hemochromatosis, Wilson's disease, and primary biliary cirrhosis. Finally, a liver biopsy should be always included in the diagnostic flowchart of INCPH.

\section{What are the histological findings in liver biopsy specimens from patients with INCPH?}

Liver biopsy is essential in the diagnostic flowchart of INCPH to exclude the diagnosis of liver cirrhosis, severe fibrosis, and rule out liver diseases known to cause portal hypertension in absence of cirrhosis (Table 1). The biopsy sample can be obtained either via the percutaneous or the trans-jugular approach; however, the latter method requires more extensive supplies and experience, and generally yields smaller and fragmented tissue samples as compared to the percutaneous approach.

Table I Principal causes of noncirrhotic portal hypertension

\begin{tabular}{lll}
\hline Presinusoidal & Sinusoidal & Postsinusoidal \\
\hline Idiopathic noncirrhotic portal hypertension & Drug induced & Budd-Chiari syndrome \\
Biliary diseases (primary biliary cirrhosis; primary sclerosing cholangitis) & Alcoholic liver damage & Veno-occlusive disease \\
Neoplastic and non-neoplastic occlusion of the portal vein & Nonalcoholic steatohepatitis & Hypervitaminosis A \\
Schistosomiasis & Viral hepatitis & Primary vascular malignancies \\
Polycystic disease & Amyloid & Epithelioid hemangioendothelioma and \\
Arteriovenous fistulas & Infiltrative diseases & angiosarcoma \\
Congenital hepatic fibrosis & Visceral leishmaniasis & \\
& Gaucher's disease & \\
& Acute fatty liver of pregnancy \\
\hline
\end{tabular}


Although there are no pathognomonic histopathologic features of INCPH, a number of microscopic lesions, both within portal tracts and in the liver parenchyma, are frequently associated with this condition. These are highlighted using hematoxylin and eosin, reticulin stain, and at least one connective tissue stain (ie, Picrosirius red, Masson trichrome, Elastic-Van Gieson) are performed on biopsy samples. ${ }^{6}$ Lesions observed at the level of portal tracts include 1) obliterative portal venopathy (or phlebosclerosis), defined as obliteration or stenosis, with fibrosis or medial hypertrophy of portal vein branches, generally affecting medium-sized and preterminal portal veins (Figure 1A-C); 2) portal fibrosis (Figure 1A) with portal tracts that are often small and rounded, without inflammation; 3) paraportal shunting vessels, that is, dilated, thin-walled aberrant vascular channels herniating from the portal tracts into the surrounding parenchyma (Figure 1D); 4) portal venules dilatation, that is, enlarged portal branches which are at least three times greater than the size of the bile duct (Figure 1E); and 5) increased number of portal vascular channels (Figure 1F). Interestingly, obliterative portal venopathy can be observed in liver biopsies even before the appearance of signs of portal hypertension.
Thus, it is important to recognize this lesion on histology and follow-up subjects afterward. ${ }^{11}$

The liver parenchyma frequently shows sinusoidal dilatation, defined as a sinusoidal lumen that is wider than one liver cell plate. ${ }^{16}$ This alteration generally affects multiple lobules within liver biopsy specimens and is associated with a thin rim of perisinusoidal fibrosis (Figure 2A). In the setting of $\mathrm{NCPH}$, sinusoidal dilation is interpreted as a nonspecific feature of impaired portal venous flow. A less frequent finding, which can be observed in liver biopsies, is NRH defined as parenchymal micronodular transformation, due to the presence of areas of hyperplastic hepatocytes alternating with atrophic, compressed liver plates, in the absence of fibrous septa. ${ }^{17} \mathrm{NRH}$ is often a subtle change, which can be highlighted by reticulin stain (Figure 2B). Less frequent findings, which can be observed in INCPH, include evidence of organizing thrombosis of portal vein branches within medium-sized and large portal tracts (Figure 2C) and small platelet deposits in the sinusoids (Figure 2D). These findings are in line with the presence of an obstructive portal microvasculopathy as the main pathogenic mechanism of INCPH, which, in turn, would cause liver nodular hyperplasia, as a consequence of focal liver ischemic damage. ${ }^{17}$

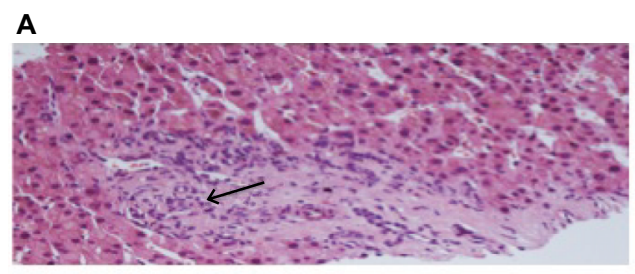

B

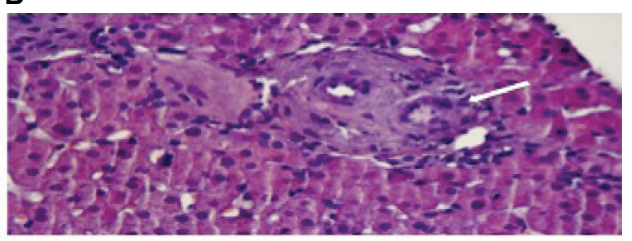

C

D
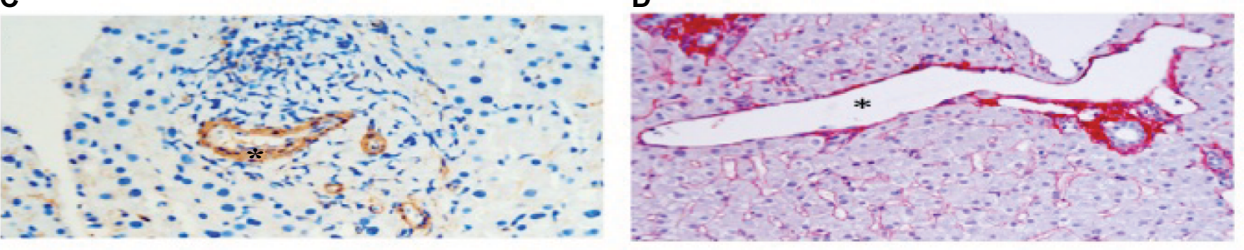

E

$\mathbf{F}$
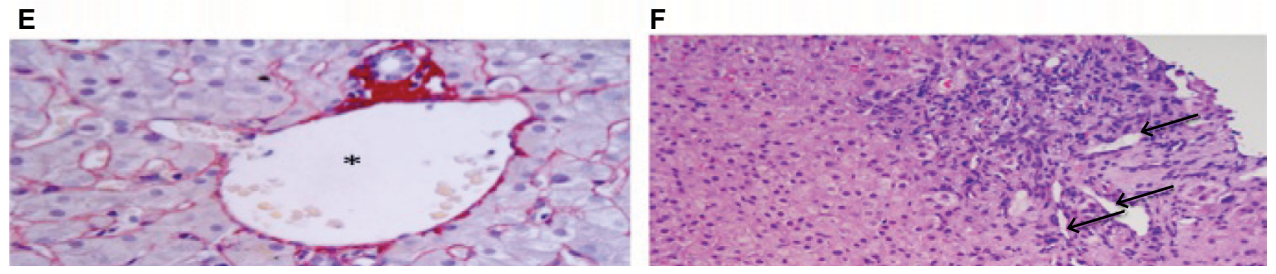

Figure I Histologic features of the portal tracts in INCPH.

Notes: (A) Obliterative venopathy: portal vein with a reduced lumen (arrow) within a fibrotic portal tract; hematoxylin and eosin stain, original magnification $\times$ I0. (B) Obliterative venopathy: a fibrotic portal tract (white arrow) with a rounded contour and a small portal branch showing a thickened wall (arterialization): hematoxylin and eosin stain, original magnification $\times 20$ (C) Obliterative venopathy: immunostain with antismooth muscle actin antibodies highlights smooth muscle cells hyperplasia in portal vein branch arterialization (asterisk); original magnification $\times 20$. (D) Paraportal shunt: dilated, thin-walled portal vascular channel herniating into the surrounding parenchyma (asterisk); picrosirius red stain, original magnification $\times 10$. (E) Marked portal vein dilation: the enlarged portal branch (asterisk) is at least three times greater than the size of the bile duct; picrosirius red stain, original magnification $\times 20$. (F) Increased number of portal vascular channels (arrows); hematoxylin and eosin stain, original magnification $\times 10$. Abbreviation: INCPH, idiopathic noncirrhotic portal hypertension. 
A

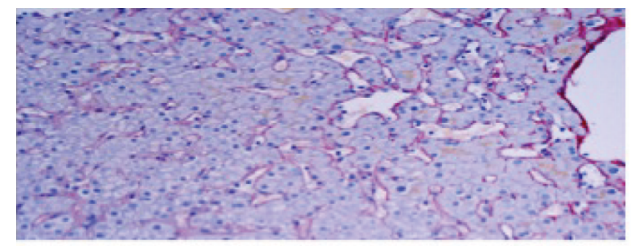

C

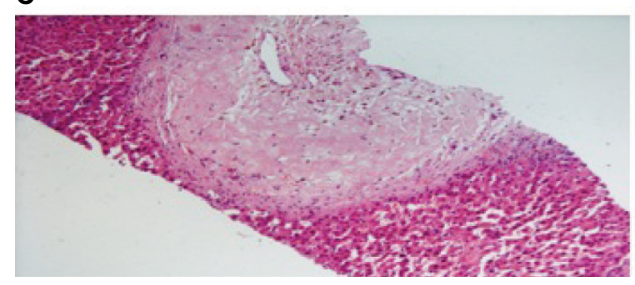

B

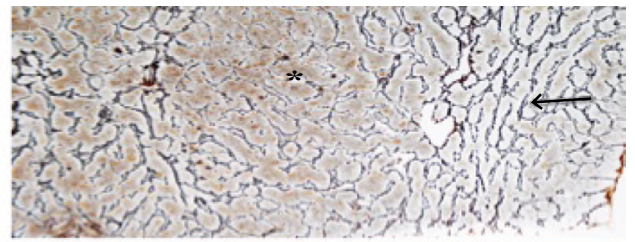

D

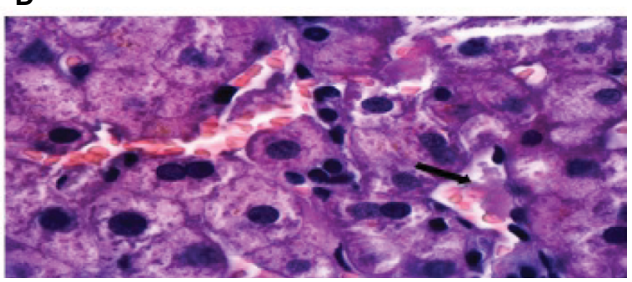

Figure 2 Histologic features of the liver parenchyma in INCPH.

Notes: (A) Sinusoidal dilatation with perisinusoidal fibrosis: dilated sinusoids are wider than one liver cell plate and are rimmed by a thin layer of collagen; picrosirius red stain, original magnification $\times 10$. (B) Nodular regeneration: hyperplastic hepatocytes (asterisk) are surrounded by atrophic hepatocytes (arrow), in absence of fibrous septa; reticulin stain, original magnification $\times 10$. (C) Organizing thrombus within a medium-sized portal branch; hematoxylin and eosin stain, original magnification $\times 5$; (D) Platelet deposits within sinusoids (arrow); hematoxylin and eosin stain, original magnification $\times 100$.

Abbreviation: INCPH, idiopathic noncirrhotic portal hypertension.

\section{How uncommon is INCPH in the Western world?}

$\mathrm{INCPH}$ is more prevalent in developing countries and socioeconomically disadvantaged individuals., ${ }^{4,9,18,19}$ In India, INCPH accounted for $23 \%$ of patients with portal hypertension in $1980 \mathrm{~s}$ but only $5.6 \%$ more recently. ${ }^{13,20} \mathrm{In}$ Japan, the incidence rate of INCPH was $0.75 / 10^{6}$ population/year in $1985 .{ }^{21}$ Two more recent Japanese nationwide epidemiological surveys collected 322 patients treated in 2,208 departments in 1998 and 229 patients treated in 1,885 departments in 2004. ${ }^{22}$ In Europe and US, this condition is more prevalent in female (M:F=1:3), while in India it seems to be predominant in male sex. ${ }^{23}$ In the Western world, INCPH might be responsible for only $3 \%-5 \%$ of cases of portal hypertension. ${ }^{6}$

Bacterial infection of the gut with repeated septic embolization and subsequent obstruction of small portal veins have been suggested to account for the high prevalence of INCPH in low socioeconomic areas with a high abdominal infection rate at birth and in early childhood. Improvements in hygiene and living standards may explain the decreasing incidence of INCPH in India and Japan during the last decades, and the low prevalence of the disease in Western countries. However, the lack of a national database of patients with INCPH prevents an accurate calculation of its prevalence. Moreover, the low reported prevalence of this condition may be also explained by fact that liver cirrhosis is the main cause of portal hypertension in the West and is suspected and diagnosed more easily. Patients with INCPH are often classified as cirrhotic and it makes INCPH underestimated.

\section{In which patients should INCPH be suspected? \\ In patients with compensated cryptogenic cirrhosis}

The diagnosis of INCPH is based on the finding of portal hypertension with patency of the portal and hepatic veins in the absence of known causes of liver damage. These features coincide with those required for the diagnosis of cryptogenic cirrhosis. Usually, patients with INCPH have no signs of liver damage but transaminases or cholestasis enzymes could sometimes be elevated, while the liver synthetic capacity is usually preserved. This makes it difficult to distinguish between INCPH and compensated cirrhosis, in which liver function is still preserved. In both compensated cirrhosis and INCPH, the only laboratory abnormalities observed, such as anemia, leukopenia, and thrombocytopenia, may be the consequences of hypersplenism. At the abdominal ultrasound, the patients affected by INCPH show signs of portal hypertension and, because of the presence of NRH, the liver surface often appears irregular and indistinguishable from a cirrhotic liver.

Table 2 reports the comparison among clinical, laboratory, and ultrasound findings observed in patients with biopsy proven cryptogenic cirrhosis and INCPH. In patients with $\mathrm{INCPH}$, the spleen diameter was significantly higher than in cirrhotic patients. INCPH patients have abnormal levels 
Table 2 Comparison between patients with compensated cryptogenic and biopsy proven INCPH

\begin{tabular}{|c|c|c|c|}
\hline & $\begin{array}{l}\text { Cryptogenic } \\
\text { cirrhosis Class A } \\
\text { Child-Pugh }(n=19)\end{array}$ & $\begin{array}{l}\text { INCPH } \\
(n=20)\end{array}$ & $P$ \\
\hline Age & $58.7 \pm 10.6$ & $45.8 \pm 16$ & 0.0005 \\
\hline Sex (male/female) & $6 / 13$ & $13 / 7$ & 0.03 \\
\hline Bilirubin (mg/dL) & $1.13 \pm 0.6$ & $1.2 \pm 1.1$ & 0.8 \\
\hline Albumin $(g / d L)$ & $3.6 \pm 0.5$ & $4.2 \pm 0.6$ & 0.005 \\
\hline $\begin{array}{l}\text { Patients with albuminemia } \\
<3.5 \mathrm{~g} \%, \mathrm{n}(\%)\end{array}$ & $5(26.3)$ & 0 & 0.01 \\
\hline ALT, UI/L & $86 \pm 222$ & $33 \pm 20.6$ & 0.29 \\
\hline Alkaline phosphatase (UI/L) & $131.3 \pm 65.2$ & $150.7 \pm 78.6$ & 0.4 \\
\hline Cholinesterasis (UI/L) & $4,504 \pm|42|$ & $6,906 \pm 2153$ & 0.0002 \\
\hline $\begin{array}{l}\text { Patients with low } \\
\text { cholinesterasis, n (\%) }\end{array}$ & $3(16)$ & 0 & 0.06 \\
\hline INR & $1.31 \pm 0.3$ & $1.21 \pm 0.37$ & 0.35 \\
\hline Platelets $\left(\times 10^{3} / \mu \mathrm{L}\right)$ & $115 \pm 46$ & $103 \pm 74$ & 0.54 \\
\hline $\begin{array}{l}\text { Patients with esophageal } \\
\text { varices, } \mathrm{n}(\%)\end{array}$ & $14(73)$ & I5 (75\%) & 0.7 \\
\hline \multicolumn{4}{|l|}{$\begin{array}{l}\text { Clinical manifestation at } \\
\text { diagnosis, } \mathrm{n}(\%)\end{array}$} \\
\hline Splenomegaly & $14(74)$ & $18(90)$ & 0.1 \\
\hline Ascites & $6(31.5)$ & $5(25)$ & 0.6 \\
\hline Variceal bleeding & $8(42)$ & $6(30)$ & 0.4 \\
\hline \multicolumn{4}{|c|}{ Abdominal ultrasound data } \\
\hline $\begin{array}{l}\text { Longitudinal spleen } \\
\text { diameter }(\mathrm{cm})\end{array}$ & $14.3 \pm 2.8$ & $17.7 \pm 5.7$ & 0.03 \\
\hline $\begin{array}{l}\text { Longitudinal liver } \\
\text { diameter }(\mathrm{cm})\end{array}$ & $13.2 \pm 1.23$ & $15.54 \pm 2.95$ & 0.009 \\
\hline $\begin{array}{l}\text { Portal vein } \\
\text { diameter }(\mathrm{mm})\end{array}$ & $12.8 \pm 2.5$ & $14.9 \pm 3$ & 0.04 \\
\hline
\end{tabular}

Notes: Data presented as mean \pm SD unless otherwise specified.

Abbreviations: ALT, alanine aminotransferase; INCPH, idiopathic noncirrhotic portal hypertension; INR, international normalized ratio; SD, standard deviation.

of liver synthesized proteins less frequently than cirrhotic patients. However, overlap exists making difficult the distinction between INCPH and cryptogenic cirrhosis in the single patient.

Imaging methods, such as computed tomography, magnetic resonance imaging, or ultrasound examination, have poor sensitivity and specificity for the diagnosis of INCPH and in distinguishing these patients from those affected by cirrhosis. Doppler ultrasonography will show a liver with an increased longitudinal diameter and heterogeneous parenchyma and nodular surface. When visible, regenerative nodules are small and isoechoic. ${ }^{24}$ Hyperechoic nodules have been reported in very rare cases of INCPH with $\mathrm{NRH} .{ }^{25} \mathrm{On}$ computed tomography, regenerative nodules remain isodense or hypodense in both arterial and portal venous phases, distinguishing NRH from focal nodular hyperplasia and adenomas. ${ }^{26}$ At magnetic resonance, regenerative nodules appear hyperintense on T1-weighted images and iso- or hypointense on T2-weighted images. ${ }^{27-29}$
Transient elastography may help to rule out cirrhosis. The finding of liver stiffness values lower than $12-14 \mathrm{kPa}$ in the presence of clear signs of portal hypertension should raise the suspicion of INCPH ${ }^{30,31}$ as well as an increased spleen/ liver stiffness ratio. ${ }^{32}$

While portal hypertension due to cirrhosis is associated with an elevated HVPG in INCPH, the HVPG is not always elevated ${ }^{33}$ and the hemodynamic evaluation shows a significant difference between the HVPG and the portal vein pressure gradient consistent with a significant presinusoidal component of the portal hypertension.

The earlier considerations support the indication of liver biopsy in any patients with portal hypertension of unknown origin and patent hepatic and portal vein, especially if the patient has a preserved liver function and low stiffness value. The histological distinction between cirrhosis and INCPH is feasible based on the presence/absence of architectural alterations and significant fibrosis.

\section{In patients affected by diseases known to be associated with INCPH}

INCPH is frequently found in patients affected by the diseases listed in Table 3. In some cases, INCPH is believed to be associated more with the treatment of the disease than the disease itself. Among 287 patients with INCPH collected in Europe, 152 (53\%) had an associated disease. Strictly speaking, the term "idiopathic" should be reserved to the cases in whom the associated diseases are absent. If we believe that portal hypertension is causally related to the presence of other diseases, the term noncirrhotic portal hypertension associated with (or secondary to) a given disease should be more appropriate. However, it has been suggested to use the term idiopathic also in patients with noncirrhotic portal hypertension associated with other disorders or medications. ${ }^{6}$ The uncertainty in the pathogenesis of INCPH and the similarity between the histological alterations observed in patients with portal hypertension associated or not with another disease probably justify this suggestion.

A practical consequence is that in patients affected by diseases known to be associated with INCPH, the active searching of signs of portal hypertension would be suggested. However, the prevalence of INCPH among unselected patients with other disease is largely unknown. INCPH has been reported in 1\% of HIV patients in India ${ }^{34}$ and in $4 \%$ of patients affected by primary immunodeficiency in Italy ${ }^{35}$ but data on the prevalence are largely lacking.

On the other hand, once the diagnosis of INCPH is made, an active searching of the diseases listed in Table 3 would be 
Table 3 Diseases associated with INCPH

\begin{tabular}{|c|c|}
\hline Disease type & Disease name or cause \\
\hline $\begin{array}{l}\text { Acquired and } \\
\text { congenital } \\
\text { immunodeficiency }\end{array}$ & $\begin{array}{l}\text { HIV } 15,37-42 \\
\text { Primary antibody-deficiency syndrome } \\
35,43,44\end{array}$ \\
\hline Genetic disorders & $\begin{array}{l}\text { Cystic fibrosis }{ }^{45-48} \\
\text { Adams-Oliver syndrome } \\
\text { Turner's disease }^{6}\end{array}$ \\
\hline $\begin{array}{l}\text { Hematologic } \\
\text { disease }^{49-55}\end{array}$ & $\begin{array}{l}\text { Myeloproliferative disorders (polycythemia } \\
\text { vera, chronic myelogenous leukemia, essential } \\
\text { thrombocythemia) } \\
\text { Myeloid metaplasia } \\
\text { Lymphoproliferative conditions (Hodgkin's } \\
\text { disease, non-Hodgkin's lymphoma, chronic } \\
\text { lymphocytic leukemia, and multiple myeloma) } \\
\text { Spherocytosis }\end{array}$ \\
\hline $\begin{array}{l}\text { Autoimmune } \\
\text { disease }^{56,57}\end{array}$ & $\begin{array}{l}\text { Rheumatoid arthritis } \\
\text { Systemic lupus erythematosus } \\
\text { Systemic sclerosis } \\
\text { Scleroderma }\end{array}$ \\
\hline Gut diseases & $\begin{array}{l}\text { Celiac disease }^{58} \\
\text { Inflammatory bowel disease }{ }^{59}\end{array}$ \\
\hline Drug and toxins ${ }^{60-63}$ & $\begin{array}{l}\text { Azathioprine, 6-thioguanine, arsenic as } \\
\text { Fowler's solution, oxaliplatin, busulfan, cytosine } \\
\text { arabinoside, cyclophosphamide, thioguanine, } \\
\text { bleomycin, chlorambucil doxyrubicin carmustine }\end{array}$ \\
\hline Thrombophilia $9,51,64$ & $\begin{array}{l}\text { Myeloproliferative neoplasm, protein S or C } \\
\text { deficiency, antiphospholipid antibodies, lupus } \\
\text { anticoagulant, factor V Leiden, prothrombin } \\
\text { mutation }\end{array}$ \\
\hline
\end{tabular}

Abbreviation: INCPH, idiopathic noncirrhotic portal hypertension.

useful. Again, the evolution of portal hypertension when an associated disease is diagnosed and treated is also unknown.

\section{In patients with prothrombotic disorders}

The relationship between INCPH and prothrombotic diseases is suggested by the high prevalence of hypercoagulability observed in the different series. In a French population described in 2002, ${ }^{9}$ a prothrombotic disorder (myeloproliferative neoplasm, protein $\mathrm{S}$ or $\mathrm{C}$ deficiency, anticardiolipin antibodies) was found in $50 \%$ of patients. Moreover, the presence of obliterative portal venopathy in liver biopsies from patients with INCPH suggests the possibility that thrombotic events in the portal branches may be the anatomical base for INCPH development. Finally, patients with INCPH frequently develop a portal vein thrombosis during the followup, although this finding may be attributed to the low portal vein flow secondary to the presinusoidal increment of hepatic resistance. In the French series, 13 patients developed portal vein thrombosis after a median of 7.6 years from diagnosis. Similarly, a report from Turkey described extrahepatic portal vein thrombosis in seven of 34 (20\%) patients with INCPH over a 5 -year follow-up period. ${ }^{36}$ Anticoagulation has been consequently been proposed as a treatment for patients with INCPH.

The relationship between INCPH and hypercoagulation raises the possibility that a patient with portal hypertension attributed to portal vein thrombosis may be actually affected by an undiagnosed INCPH, preexisting to the development of portal vein thrombosis. Actually in $\sim 25 \%$ of the patients with portal vein thrombosis, the underlying cause remains unknown despite the active searching of local or systemic diseases known to be associated with a thrombotic event. In patients with portal vein thrombosis of unknown origin, and also in those in whom a prothrombotic disease is diagnosed, liver biopsy is seldom performed and thus the diagnosis of INCPH as the preexisting condition for portal vein thrombosis may be missed.

\section{In patients with chronic ALT/AST elevation of unknown origin}

Two recent papers suggest that the histological lesions commonly described in patients with INCPH can also be observed in patients with chronic unexplained alteration of liver enzymes and no portal hypertension. Cazals-Hatem et $\mathrm{al}^{11}$ by reviewing 59 biopsies with histological diagnosis of obliterative portal venopathy (one of the most characteristic features of INCPH) found that among them 15 patients had no signs of portal hypertension at the initial observation. However, six of them developed portal hypertension during the follow-up. More recently, Guido et $\mathrm{al}^{12}$ by reviewing 482 liver biopsies from patients with chronic ALT/ AST elevation without cirrhosis and portal hypertension described histological alterations similar to those observed in patients with INCPH in 94 patients (19\%). Interestingly, in this series, some patients were affected by diseases known to be associated with INCPH, such as autoimmune disorders (13\% of patients) and prothrombotic disorders ( $6 \%$ of patients). These observations, if confirmed, suggest that patients with INCPH may be searched also among the patients with chronic liver function test abnormalities of unknown etiology and no signs of portal hypertension and that at least a proportion of these patients may develop portal hypertension later on. ${ }^{11}$

Again, the lack of awareness of this possibility as well as the lack of familiarity of the histological features of INCPH among the pathologists should contribute to the underestimation of this condition. 


\section{Conclusion}

INCPH is probably under recognized and underestimated in the Western world. Physicians should learn to search this condition in a number of clinical settings, including cryptogenic cirrhosis, diseases known to be associated with INCPH, drug administration, and even chronic alterations in liver function tests. Once INCPH is clinically suspected, liver histology became mandatory for the correct diagnosis. However, pathologists should be familiar with the histological features of INCPH, especially in cases in which histology is not only requested to exclude liver cirrhosis.

A number of issues remain to be clarified, including the etiology and pathogenesis of INCPH, its natural history, prognosis, and management. Cooperative studies are probably needed to solve these issues in a clinical condition, which, although underestimated, remains an infrequent disorder.

\section{Disclosure}

The authors report no conflicts of interest in this work.

\section{References}

1. Banti G. Splenomegalie mit Leberzirrhose Beitrage zur Pathologischen. Anat Allgemeinea Pathol. 1889;24:21-33.

2. Ramalingaswami V, Wig KL, Sama SK. Cirrhosis of the liver in northern India. A clinicopathological study. Arch Intern Med. 1962;110:350-358

3. Basu AK, Boyer J, Bhattacharya R, Basu Mallick KC, Sen Gupta LP. Non-cirrhotic portal fibrosis with portal hypertension: a new syndrome. I. Clinical and function studies and result of operations. II. Histopathological studies. Indian J Med Res. 1967;55(4):336-339.

4. Mikkelsen WP, Edmondson HA, Peters RL, Redeker AG, Reynolds TB. Extra- and intra-hepatic portal hypertension without cirrhosis (hepatoportal sclerosis). Ann Surg. 1965;162(4):602-620.

5. Boyer JL, Sen Gupta KP, Biswas SK, et al. Idiopathic portal hypertension. Comparison with the portal hypertension of cirrhosis and extrahepatic portal vein obstruction. Ann Intern Med. 1967;66(1):41-68.

6. Schouten JN, Garcia-Pagan JC, Valla DC, Janssen HL. Idiopathic non cirrhotic portal hypertension. Hepatology. 2011;54(3):1071-1081.

7. Schouten JN, Nevens F, Hansen B, et al. Idiopathic non cirrhotic portal hypertension is associated with poor survival: results of a long-term cohort study. Aliment Pharmacol Ther. 2012;35(12):1424-1433.

8. Siramolpiwat S, Seijo S, Miquel R, et al. Idiopathic portal hypertension: natural history and long-term outcome. Hepatology. 2014;59(6):2276-2285

9. Hillaire S, Bonte E, Denninger $\mathrm{MH}$, et al. Idiopathic non-cirrhotic intrahepatic portal hypertension in the West: a re-evaluation in 28 patients. Gut. 2002;51(2):275-280.

10. Eapen CE, Nightingale P, Hubscher SG, et al. Non-cirrhotic intrahepatic portal hypertension: associated gut diseases and prognostic factors. Dig Dis Sci. 2011;56(1):227-235.

11. Cazals-Hatem D, Hillaire S, Rudler M, et al. Obliterative portal venopathy: portal hypertension is not always present at diagnosis. $J$ Hepatol. 2011;54(3):455-461.

12. Guido M, Sarcognato S, Sonzogni A, et al. Obliterative portal venopathy without portal hypertension: an underestimated condition. Liver Int. Epub 2015 Sep 6.
13. Goel A, Elias JE, Eapen CE, Ramakrishna B, Elias E. Idiopathic NonCirrhotic Intrahepatic Portal Hypertension (NCIPH) - newer insights into pathogenesis and emerging newer treatment options. J Clin Exp Hepatol. 2014;4(3):247-256.

14. Nicoletti V, Gioia S, Riggio O, et al. Hepatic encephalopathy in patients with non-cirrhotic portal hypertension: description, prevalence and risk factors. Dig Liv Dis. In press 2016.

15. Schouten JNL, Verheij J and Seijo S. Idiopathic non-cirrhotic portal hypertension: a review. Orphanet J Rare Dis. 2015;10:67.

16. Marzano M, Cazals-Hatem D, Rautou PE, Valla DC. The significance of nonobstructive sinusoidal dilatation of the liver: impaired portal perfusion or inflammatory reaction syndrome. Hepathology. 2015;62(3):956-963.

17. Wanless IR. Micronodular transformation (nodular regenerative hyperplasia) of the liver: a report of 64 cases among 2500 autopsies and a new classification of benign hepatocellular nodules. Hepatology. 1990;11(5):787-797.

18. Dhiman RK, Chawla Y, Vasishta RK, et al. Non-cirrhotic portal fibrosis (idiopathic portal hypertension): experience with 151 patients and a review of the literature. J Gastroenterol Hepatol. 2002;17(1):6-16.

19. Pande C, Kumar A, Sarin SK. Non-cirrhotic portal fibrosis: a clinical profile of 366 patients. Am J Gastroenterol. 2006;101:S191.

20. Krasinskas AM, Eghtesad B, Kamath PS, Demetris AJ, Abraham SC. Liver transplantation for severe intrahepatic noncirrhotic portal hypertension. Liver Transpl. 2005;11(6):627-634

21. Iwata $H$, Nishikawa A, Tanaka $H$, et al. National survey on idiopathic portal hypertension. In: Kameda H, editor. 1985 Report of the Research Committee on Aberrant Portal Hemodynamics. Tokyo: Ministry of Health and Welfare; 1986:117-129.

22. Murai Y, Ohfuji S, Fukushima W, et al. Prognostic factors in patients with idiopathic portal hypertension: Two Japanese nationwide epidemiological surveys in 1999 and 2005. Hepatol Res. 2012;42(12):1211-1220.

23. Okudaira M, Ohbu M, Okuda K. Idiopathic portal hypertension and its pathology. Semin Liver Dis. 2002;22(1):59-72.

24. Clouet M, Boulay I, Boudiaf M, et al. Imaging features of nodular regenerative hyperplasia of the liver mimicking hepatic metastases. Abdom Imaging. 1999;24(3):258-261.

25. Casillas C, Martí-Bonmatí L, Galant J. Pseudotumoral presentation of nodular regenerative hyperplasia of the liver: imaging in five patients including MR imaging. Eur Radiol. 1997;7(5):654-658.

26. Mahamid J, Miselevich I, Attias D, Laor R, Zuckerman E, Shaoul R. Nodular regenerative hyperplasia associated with idiopathic thrombocytopenic purpura in a young girl: a case report and review of the literature. J Pediatr Gastroenterol Nutr. 2005;41(2):251-255.

27. Hartleb M, Gutkowski K, Milkiewicz P. Nodular regenerative hyperplasia: evolving concepts on underdiagnosed cause of portal hypertension. World J Gastroenterol. 2011;17(11):1400-1409.

28. Horita T, Tsutsumi A, Takeda T, et al. Significance of magnetic resonance imaging in the diagnosis of nodular regenerative hyperplasia of the liver complicated with systemic lupus erythematosus: a case report and review of the literature. Lupus. 2002;11(3):193-196.

29. Rha SE, Lee MG, Lee YS, et al. Nodular regenerative hyperplasia of the liver in Budd-Chiari syndrome: CT and MR features. Abdom Imaging. 2000;25(3):255-258.

30. Seijo S Reverter E, Berzigotti A, et al. Idiopathic portal hypertension: impact of hepatic vein catheterization and transient elastography on its diagnosis. J Hepatol. 2010;52:S172.

31. Ziol M, Handra-Luca A, Kettaneh A, et al. Noninvasive assessment of liver fibrosis by measurement of stiffness in patients with chronic hepatitis C. Hepatology. 2005;41(1):48-54.

32. Furuichi Y, Moriyasu F, Taira J, et al. Noninvasive diagnostic method for idiopathic portal hypertension based on measurements of liver and spleen stiffness by ARFI elastography. J Gastroenterol. 2013;48(9):1061-1068.

33. Bissonnette J, Généreux A, Côté J, et al. Hepatic hemodynamics in 24 patients with nodular regenerative hyperplasia and symptomatic portal hypertension. J Gastroenterol Hepatol. 2012;27(8):1336-1340. 
34. Khanna R, Sarin SK. Non-cirrhotic portal hypertension: Diagnosis and management. J Hepatol. 2014;60(2):421-441.

35. Pulvirenti F, Pentassuglio I, Milito C, et al. Idiopathic non cirrhotic portal hypertension and spleno-portal axis abnormalities in patients with severe primary antibody deficiencies. J Immunol Res. 2014;2014:672458.

36. Köksal AS, Köklü S, Ibiş M, et al. Clinical features, serum interleukin-6, and interferon-gamma levels of 34 Turkish patients with hepatoportal sclerosis. Dig Dis Sci. 2007;52(12):3493.

37. Vispo E, Moreno A, Maida I, et al. Noncirrhotic portal hypertension in HIV-infected patients: unique clinical and pathological findings. AIDS. 2010;24(8):1171-1176.

38. Schouten JN, Van der Ende ME, Koëter T, et al. Risk factors and outcome of HIV-associated idiopathic non cirrhotic portal hypertension. Aliment Pharmacol Ther. 2012;36(9):875.

39. Cachay ER, Peterson MR, Goicoechea M, Mathews WC. Didanosine exposure and noncirrhotic portal hypertension in a HIV clinic in North America: a follow-up study. Br J Med Med Res. 2011;1(4):346.

40. Vispo E, Morello J, Rodriguez-Novoa S, Soriano V. Noncirrhotic portal hypertension in HIV infection. Curr Opin Infect Dis. 2011;24(1):12-18.

41. Mallet VO, Varthaman A, Lasne D, et al. Acquired autoimmune protein $S$ paucity and secondary thrombophilia appear to be causes of obliterative portal venopathy and compensatory nodular regenerative hyperplasia in HIV-positive patients. AIDS. 2009;23(12):1511-1518.

42. Saifee S, Joelson D, Braude J, et al. Noncirrhotic portal hypertension in patients with HIV infection. Clin Gastroenterol Hepatol. 2008;6:1167-1169.

43. Malamut G, Ziol M, Suarez F, et al. Nodular regenerative hyperplasia: the main liver disease in patients with primary hypogammaglobulinemia and hepatic abnormalities. J Hepatol. 2008;48(1):74-82.

44. Ward C, Lucas M, Piris J, Collier J, Chapel H. Abnormal liver function in common variable immunodeficiency disorders due to nodular regenerative hyperplasia. Clin Exp Immunol. 2008;153(3):331-337.

45. Witters P, Libbrecht L, Roskams T, et al. Noncirrhotic presinusoidal portal hypertension is common in cystic fibrosis-associated liver disease. Hepatology. 2011;53(3):1064-1065.

46. Lewindon PJ, Shepherd RW, Walsh MJ, et al. Importance of hepatic fibrosis in cystic fibrosis and the predictive value of liver biopsy. Hepatology. 2011;53(1):193-201.

47. Debray D, Lykavieris P, Gauthier F, et al. Outcome of cystic fibrosis associated liver cirrhosis: management of portal hypertension. $J$ Hepatol. 1999;31(1):77-83.

48. Gooding I, Dondos V, Gyi KM, Hodson M, Westaby D. Variceal hemorrhage and cystic fibrosis: outcomes and implications for liver transplantation. Liver Transpl. 2005;11(12):1522-1526.

49. Wanless IR, Peterson P, Das A, Boitnott JK, Moore GW, Bernier V. Hepatic vascular disease and portal hypertension in polycythemia vera and agnogenic myeloid metaplasia: a clinicopathological study of 145 patients examined at autopsy. Hepatology. 1990;12(5):1166-1174.
50. Al-Mukhaizeem KA, Rosenberg A, Sherker AH. Nodular regenerative hyperplasia of the liver: an under-recognized cause of portal hypertension in hematological disorders. Am J Hematol. 2004;75(4):225-230.

51. Shaldon S, Sherlock S. Portal hypertension in the myeloproliferative syndrome and reticuloses. Am J Med. 1962;32:758.

52. Rosen A, Iseri O, Fishbein G, Knodell R. Nodular regenerative hyperplasia: a cause of ascites and hepatomegaly after chemotherapy for leukemia. Am J Gastroenterol. 1991;86(1):86-88.

53. Al-Mukhaizeem KA, Lamoureux E, Rosenberg A, Sherker AH. Nodular regenerative hyperplasia of the liver and focal global glomerulosclerosis associated with sickle cell anemia. Dig Dis Sci. 2002;47(2):443-447.

54. Nayyar AK, Sharma BK, Sarin SK, Malhotra P, Broor SL, Sachdev G. Characterization of peripheral blood lymphocytes in patients with non-cirrhotic portal fibrosis: a comparison with cirrhotics and healthy controls. J Gastroenterol Hepatol. 1990;5(5):554-559.

55. Tokushige K, Komatsu T, Ohzu K, Yamauchi K, Obata H. A defective autologous mixed lymphocyte reaction in patients with idiopathic portal hypertension. J Gastroenterol Hepatol. 1992;7(3):270-273.

56. Saito K, Nakanuma Y, Takegoshi K, et al. Non-specific immunological abnormalities and association of autoimmune diseases in idiopathic portal hypertension. A study by questionnaire. Hepatogastroenterology. 1993;40(2):163-166.

57. Tsuneyama K, Harada K, Katayanagi K, et al. Overlap of idiopathic portal hypertension and scleroderma: report of two autopsy cases and a review of literature. J Gastroenterol Hepatol. 2002;17(2): 217-223.

58. Austin A, Campbell E, Lane P, Elias E. Nodular regenerative hyperplasia of the liver and coeliac disease: potential role of $\operatorname{IgA}$ anticardiolipin antibody. Gut. 2004;53(7):1032-1034.

59. Calabrese E, Hanauer SB. Assessment of non-cirrhotic portal hypertension associated with thiopurine therapy in inflammatory bowel disease. $J$ Crohns Colitis. 2011;5(1):48-53.

60. Guha Mazumdar DN, Das Gupta J. Arsenic and non-cirrhotic portal hypertension. J Hepatol. 1991;13(3):376.

61. Nevens F, Fevery J, Van Steenbergen W, Sciot R, Desmet V, De Groote $\mathrm{J}$. Arsenic and non-cirrhotic portal hypertension. A report of eight cases. J Hepatol. 1990;11(1):80-85.

62. Key NS, Kelly PM, Emerson PM, Chapman RW, Allan NC, McGee JO. Oesophageal varices associated with busulphan-thioguanine combination therapy for chronic myeloid leukaemia. Lancet. 1987;2(8567): $1050-1052$.

63. Slade JH, Alattar ML, Fogelman DR, et al. Portal hypertension associated with oxaliplatin administration: clinical manifestations of hepatic sinusoidal injury. Clin Colorectal Cancer. 2009;8(4):225-230.

64. Mallet V, Varthaman A, Lasne D, et al. HIV-associated nodular regenerative hyperplasia is linked to portal obstructive venopathy and autoimmune protein S deficiency. Hepatology. 2007;46(Suppl):576A.
Hepatic Medicine: Evidence and Research

\section{Publish your work in this journal}

Hepatic Medicine: Evidence and Research is an international, peerreviewed, open access journal covering all aspects of adult and pediatric hepatology in the clinic and laboratory including the following topics: Pathology, pathophysiology of hepatic disease; Investigation and treatment of hepatic disease; Pharmacology of drugs used for the treatment

\section{Dovepress}

of hepatic disease. Issues of patient safety and quality of care will also be considered. The manuscript management system is completely online and includes a very quick and fair peer-review system, which is all easy to use. Visit http://www.dovepress.com/testimonials.php to read real quotes from published authors. 